\title{
Non-Tubularised Urethroplasty In Hypospadias And Urethrocutaneous Fistula Repair--- Buried Strip Principle Revisited
}

\author{
*Dr. Bibhas Chandra Mukhopadhyay, Dr. Krishnendumaitidr \\ Tapankumarmondal, Dr. Tapas Kumar Majhi,Dr. Shashankadhanuka, \\ Dr. Ankit Koyal \\ Department Of Urology, Nilratan Sircar Medical College And Hospital; Kolkata-14, West Bengal; India \\ Corresponding Author: *Dr. Bibhas,
}

\begin{abstract}
Aim: To study the role of the age old Denis Browne (buried strip) principle in the present era of hypospadias surgery and urethrocutaneous fistula repair along with the Tunica Vaginalis flap (TVF) to wrap the buried strip with a perurethral catheter(PUC) over it.

Material And Methods: Over a period of 9 months in 7 patients with primary hypospadias and 4 patients with urethrocutaneous fistula, developed following hypospadias surgery, i.e. total 11 patients; "buried strip" urethroplasty (i.e. without tubularization of the urethral plate) and wrapping with TV flap was done. PUC was kept for 11-21 days, still the wound is dry, for urinary diversion. Period of follow up was 3-9 months. It is an ongoing prospective study we are reporting our interim results.

Results: Amongst the 7 hypospadias patients superficial ventral skin necrosis occurred in one patient, One patient developed sutural separation ventrally followed by wound dehiscence for $<4 m m$ in size on $4^{\text {th }}$ postoperative day, that was closed primarily with a single suture with 4-0 PDS and subsequently healed well. None of them developed urine leak, UCF, meatal stenosis, testis tethering, penile torque or secondary chordee . Amongst the 4 patients with UCF repair one patient had partial dehiscence of the suture line with exposed TV flap. Overall complication in this series was about 27.2\%, that is comparable with other series (10-12) ranging from 20-35.75\%. But all of those complications were managed conservatively without any further surgical intervention. A complication requiring further surgical intervention that is considered as failure, is still nil; though follow up period of our study is short.

Conclusion: The 'buried strip' along with additional coverage with TV flap was found to be simple and effective with comparable results even in the present era of hypospadias surgery and repair of urethrocutaneous fistula repair. But a randomised controlled trial with adequate sample size and follow up for a longer duration is required to corroborate with our results.
\end{abstract}

Keywords: Denis Browne, buried strip, hypospadias, urethrocutaneous fistula, Tunica Vaginalis flap, urethroplasty

\section{Introduction}

Hypospadias is the most common congenital anomaly of penis(1). It has been recognised as a surgically treatable condition for nearly two millennia. Celsus and Galen described the condition as well as its possible surgical remedies $(2,3)$. Needless to say, surgical techniques have evolved with time. Despite of hundreds of different operations and massive advances in urethroplasty technique, certain complications still remain problematic for the modern hypospadiologist, namely, meatal stenosis, urethral stricture and perhaps most importantly urethrocutaneous fistula.

In the commonly performed tubularization of the urethral plate during urethroplasty, vascular supply of the urethral plate may be diminished due to gradual circumferential separation of the urethral plate from its bed and this ischemia may be aggravated further by unintended tension by the stitches for tubularization over a catheter(4). In our procedure, by adopting buried strip principle of Denis Browne, (5)both are avoided by keeping the strip in situ and allowing it to regenerate on a tube as a scaffold. The most popular TIP(Tubularised Incised Plate) procedure is also based on the same principle of epithelial regeneration in the gap of the incised plate to achieve the adequate calibre of neo-urethra.

The dictum, "There is nothing new in surgery not previously described", (6) is particularly true in hypospadias. The 'buried skin'" technique was firstdescribed by Dupley in 1880 but was popularised by Denis Browne in 1949(5) based upon his observations that, skin of prepuce never forms keloid, nor does the subcutaneous tissue thicken and contract following granulation and healing as is the rule elsewhere in the body. Because of this if a strip of skin is buried along the line where a new urethra is desired it will automatically form 
itself in a tube without stricture in diameter nor contraction in length. Urine must be diverted during the process of healing.(5)

Well vascularised tissue interpositioning is now a widely recognised procedure in hypospadias surgery to improve healing of the neo-urethra reducing the chance of urethrocutaneousfistula(UCF) formation or recurrence following UCF repair. Amongst the different tissues that can be used as interposition we have chosen tunica vaginalis flap(TVF) because of its several advantages and better results in comparisonwith others.(7) TVF was first described by Hosli in 1970, later it was popularised by Snow.(8)

\section{Materials And Methods}

It is a prospective study, started on September 2016, still going on (we are reporting the interim results) in the department of urology of NilratanSircar Medical College \& Hospital, Kolkata.

\section{patient selection}

All patients with hypospadias and all patients with urethrocutaneous fistula (UCF) developed followinghypospadias surgery admitted in our institute during the study period. A minimum healing period of 6 months between previous hypospadias surgery and UCF repair was allowed. Patients with previous bilateral scrotal surgery viz. hydrocele, orchiopexyetc and patients with perineal hypospadias were excluded from the study.

Total number of patients enrolled was 11, of which 7 patients were with primary hypospadias, 4 patients were with UCF developed following hypospadias surgery, in one of those patients previous operation was done in our hospital, the other three was operated in some other hospitals. Amongst hypospadias patients, 4 patients were with distal penile hypospadias, 1 patient with midpenile and 2 patients with penosrotal hypospadias. In one of the penosrotal hypospadiastwo stage repair ( in first stage chordee correction with dorsal onlay buccal mucosa grafting (BMG) in place of narrow, $<4 \mathrm{~mm}$, fibrosed urethral plate; second stage, after 3 months, TVF wrapping over the BMG with PUC placed over it) in the other patient with penoscrotal hypospadias we performed single stage repair.Amongst the UCF patients, in two patients fistula was small $<4 \mathrm{~mm}$, in 3 patients previous single attempt of repair was done, in one patient 3 attempts of urethroplasty were done previously. In none of the UCF patients there was associated urehralstricture.Two of these patients had distal penile hypospadias ( TIP was done) and two had penoscrotal hypospadias ( two stage Bracka's procedure done). Age range of our patients 1 year to 30 years, follow up period was from 3- 9 months. Patients were followed up for detection of immediate complications like skin necrosis, wound infection, wound dehiscence, urine leak, scrotal hematoma, epididymoorchitis; delayed complications viz. meatal stenosis, UCF or recurrence, testis tethering, testis atrophy, penile torque, secondary chordee, urethral stricture

FOLLOW UP--- patients are being followed up at 1,3,6 and 12 months and then 6monthly as complications like urethral stricture may develop years later with history, Physical examination,Uroflowmetry,RGU(if 2SD below normal for age as per Segura nomogram in < 12 years, for > 12 years if Qmax $<15 \mathrm{ml} / \mathrm{sec}$ ), Urethroscopic assessment in abnormal or doubtful RGU.

\section{Surgical Technique}

Under general anaesthesia a glandular staysuture was placed in long axis .A catheter of appropriate size was introduced in to urethra. A ' $U$ ' shaped incision was made encompassing the hypospadiac meatus ending in glandular 'cleft meatus' to create a rectangular Iceland of urethral plate separated from rest of penile skin after degloving. Then Gitties test was done to exclude presence of any residual chordee, if any, then dorsal plication done with 3-0 PDS at $2 \& 10$ o'clock, with this chordee was corrected in our all but one patient. That patient with penoscrotal hypospadias we had to transect the urethral plate, BMG was placed in that gap. Width of the urethral plate varied between $4 \mathrm{~mm}$ to $10 \mathrm{~mm}$ depending on the width of the 'cleft meatus'. Then a midline incision was made only at the cleft meatus for the 'hinging' (9) of the glandular urethral plate in all patients and to accommodate the PUCwithout suture tension in glanuloplasty.

A catheter(PUC) of appropriate size $(6 \mathrm{Fr}$ to $12 \mathrm{Fr}$ )was inserted into bladder and placed over the urethral plate. PUC was intended as a scaffold and less mobile in post-operative dressing for 5 to 6 days. Tunica vaginalis pedicled flap (TVPF) was harvested from right testis. We used separate transverse scrotal incision for tunnelling up the TVPF that wrapped the strip of urethral plate with PUC over it. During harvesting the TVPF it was taken care of that its distal end reach the glans without tension, its free from cremasteric fibres to avoid secondary chordee or penile torque. TVPFwas sewn not at the edge of urethral plate but to the tissue lateral to it, just as a wrap not as an onlay. Then glans wings were sutured in midline with 4-0 PDS over the urethral plate with PUC wrapped with TVPF. Dorsal hooded prepuce was refashioned and rotated to ventrum avoiding midline stitches.

In patients with urethrocutaneousfistula(UCF) a PUC of appropriate size was introduced into bladder and a circumferential incision was made around the fistula to separate it from penile skin, margin of the urethra was 
refreshed. Now TVF of adequate length was harvested and wrapped to the tissues just beyond the refreshed urethral margin and skin margin was closed over it.. Two layered compressing dressing was done after suture fixing the PUC with glans. Dressing was removed after 5 days, PUC on $12^{\text {th }}$ postoperative day, provided wound was healthy,otherwise PUC was kept till the wound was dry, in two patients with wound complications PUC was kept for 21 days.
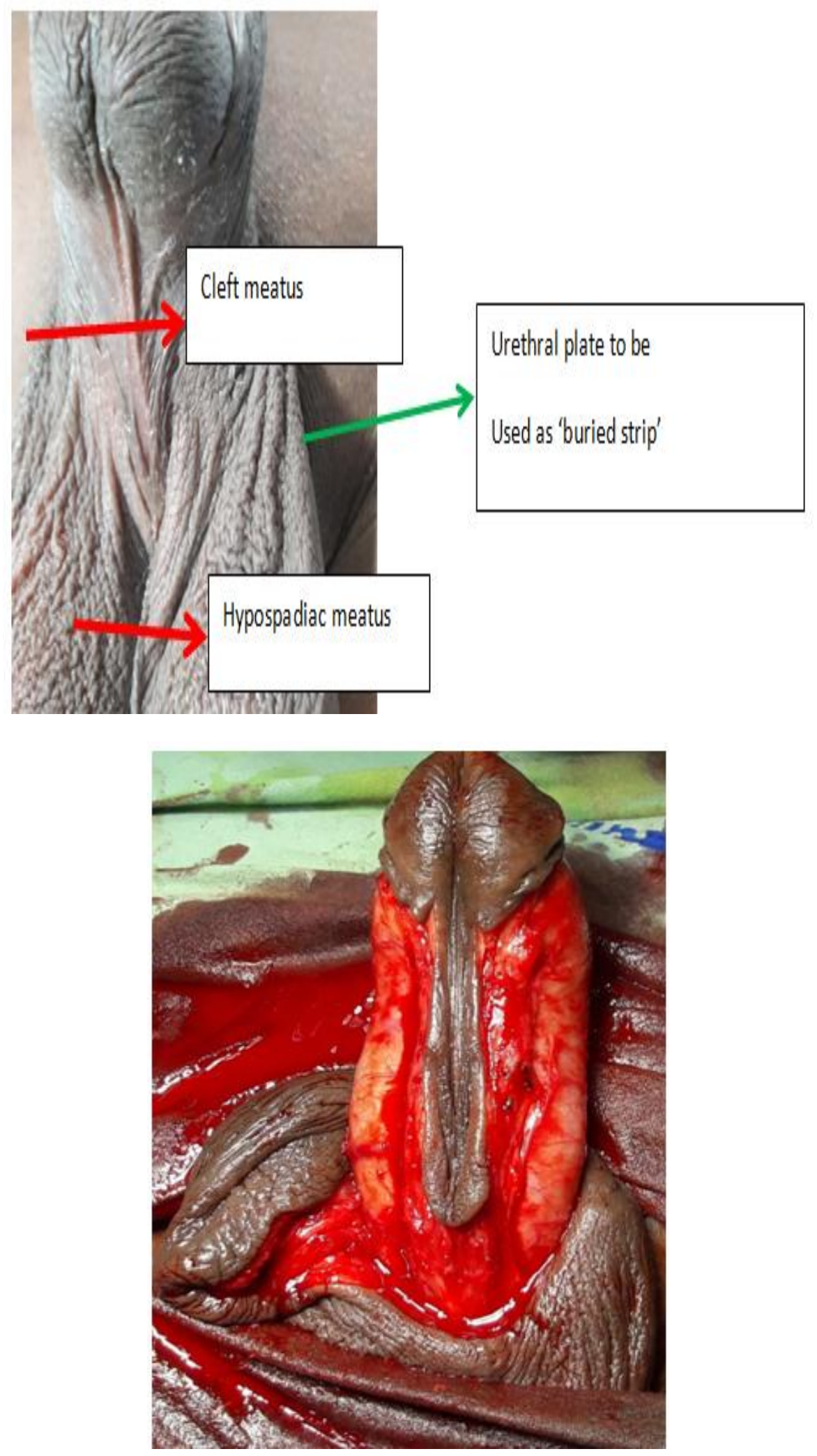


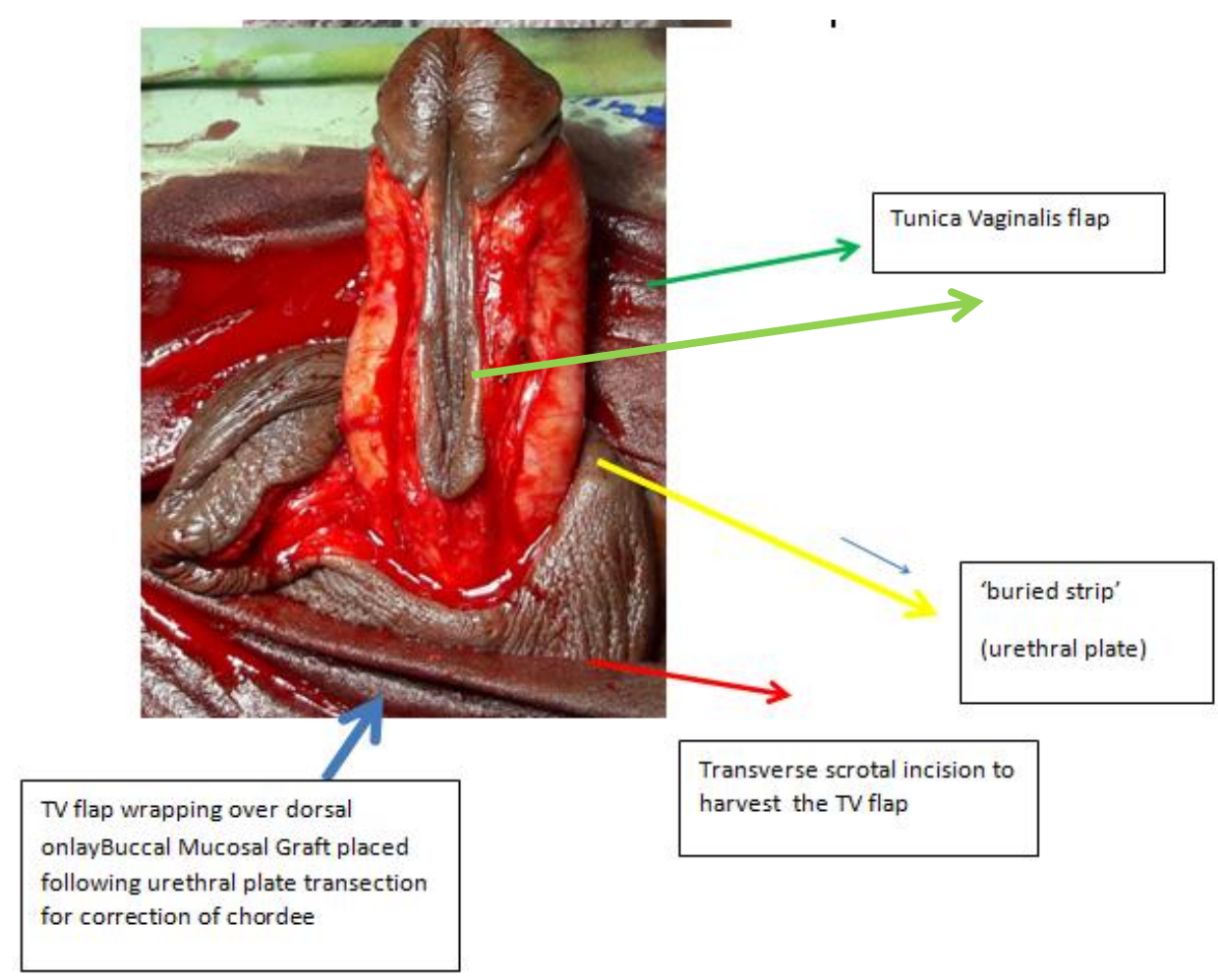

\section{Results}

Amongst the 7 hypospadias patients superficial ventral skin necrosis occurred in one patient, that healed completely within two weeks with dressing with normal saline and local application of silver nano gel. One patient developed sutural separation ventrally followed by wound dehiscence for $<4 \mathrm{~mm}$ in size on $4^{\text {th }}$ postoperative day, that was closed primarily with a single suture with 4-0 PDS and subsequently healed well. None of them developed urine leak, UCF, meatal stenosis, testis tethering, penile torque or secondary chordee . Vertical slit meatus was resulted in 6 patients. In all patients neo-meatus and glandular reconstruction maintained their position and shape respectively giving a good cosmetic outcome. Patients were satisfied with urine flow. On uroflowmetric assessment Qmax range was between $22-27 \mathrm{ml} / \mathrm{sec}$, in one of our patient with age around one year urineflow was assessed with good visual urine flow without spraying. RGU or urethroscopy was not warranted still now.

Amongst the4 patients with UCF repair one patient had partial dehiscence of the suture line with exposed TV flap. He recovered with regular dressing and urethral catheterisation for 3 weeks, in this particular patient previous three attempts of urethroplasty done outside. Overall complication in this series was about $27.2 \%$, that is comparable with other series ( 10-12) ranging from 20-35.75\%. But all of those complications were managed conservatively without any further surgical intervention. A complication requiring further surgical intervention that is considered as failure, is still nil; though follow up period of our study is short.

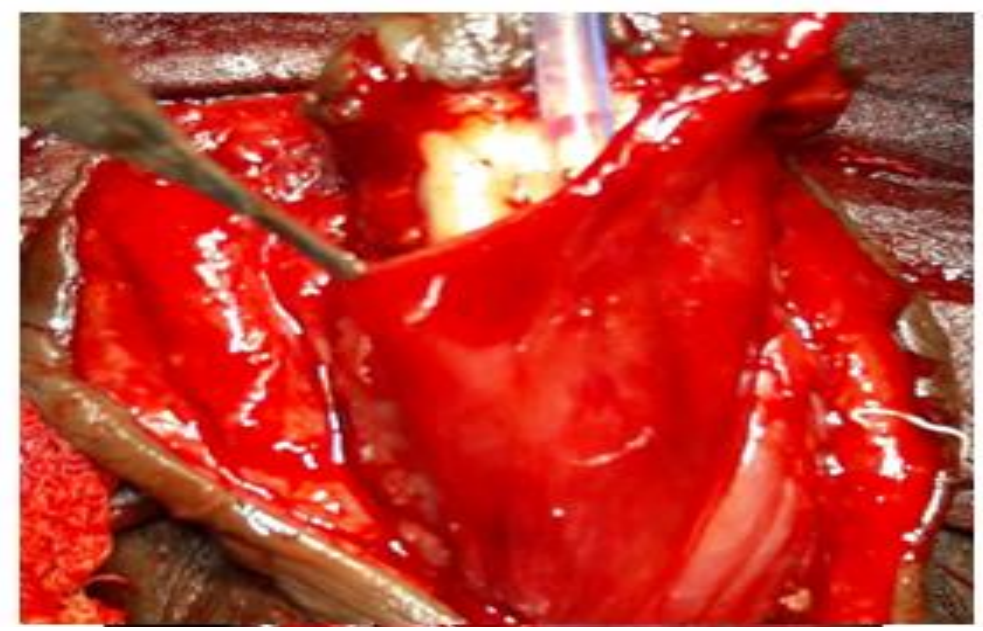



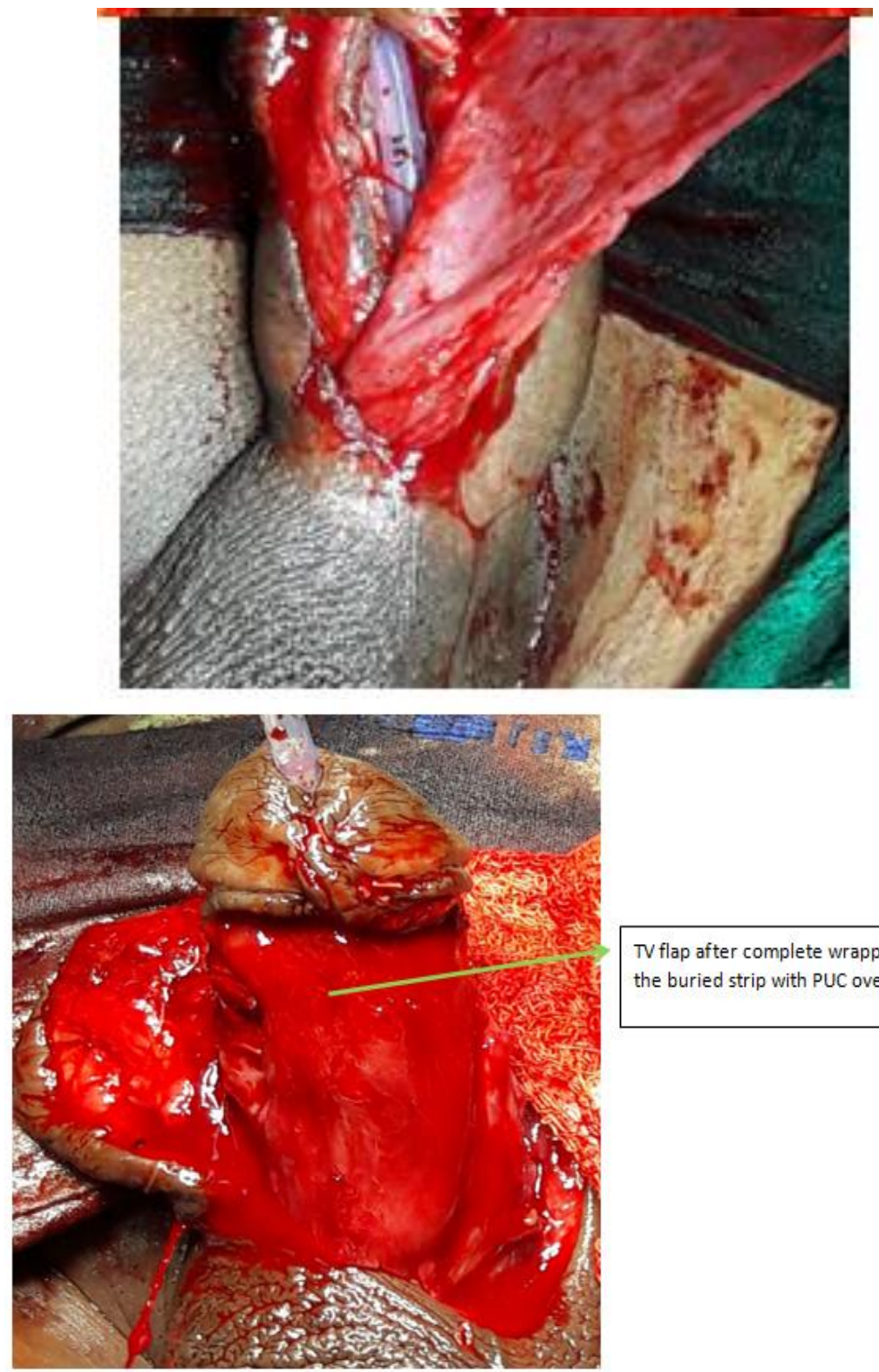

TV flap after complete wrapping of the buried strip with PUC over it

\section{Discussion}

The concept of 'buried strip' fromDupley(1880), Hamilton Russel (1915) and Denis Browne (1949) basically follows the principle of regeneration. Johanson in 1953 applied the same principle in urethroplasty for long anterior stricture of urethra $(6,13)$. According to them and to the principle of regeneration, tubularization is not mandatory. The regeneration of the epithelium will occur from a skin strip buried in to subcutaneous tissue to create a tube as the basal layer is the source of regenerating cells, some of which are stemcells. Adipose tissue in the subcutaneous layer is also a rich source of stem cells. These stem may differentiate into different type cells including endothelial cell that plays important role in neovascularisation.

The loss of popularity of the original 'buried strip' procedure was due to the high complications blamed towards the overlapping skin suture line to the buried strip and the outcome was not reproducible by other surgeons. To obviate this in 1973 Durham Smith conceptualised the 'barrier layer' (14) i.e. the well vascularised TVF what we had used, similarly rotation of thicker, more vascular dorsal penile skin to ventrum and avoiding overlapping suture lines - lacking in the procedure of Denis Browne causing high complication rate.

Many surgeon feel secure by the 'visible' tube rather than the 'virtual' concept of 'buried strip' or regenerative principle. Recently TIP has become the most popular procedure for primary hypospadias surgery. In TIP the raw area following incision in the urethral plate regenerates from the epithelial margin. Thus the TIP procedure is basically satisfying the principle of both 'tube urethroplasty' and the concept of 'buried strip'. But the sutured and repaired area showed fibrotic response which is proportional to the tension in the suture line 
causing ischemia of the urethral plate(15). So, wider $>8 \mathrm{~mm}$ urethral plate is suggested by some authors to avoid tension in suture line \& a high complicationrate of $23-55 \%(16,17)$.

\section{Conclusions}

The 'buried strip' is an old,almost abandoned and unknown to many and it is in oblivion! The trails of the popularities of Dupley, Hamilton Russel, Denis Browne, Johanson by name are still identifiable by the Hypospadiologist. But the actual procedure and regenerative concept of the 'buried strip' is forgotten by many. Notwithstanding, the recently most popular TIP procedure is indirectly validating the 'buried strip' concept in 'dignified disguise'. We identified that the 'buried strip' principle along with the additional coverage with TVF is technically simple and effective for the repair of hypospadias and urethrocutaneous fistula.

\section{Limitations Of Our Study}

Our study is limited with small sample size (11) with short duration of follow up ( 3-9 months). A randomised controlled study with a good sample size and long period of followup is essential to confirm our result and to assess the place of the age old 'buried strip' principle in modern hypospadias surgery.

conflict Of Interest— nil

\section{References}

[1]. Baskin LS. Hypospadias and urethral development. J Urol 2000;163:951-6

[2]. J.Lascaratos, A. Kostakopoulos, and G. Louras, "penile surgical techniques describrdbyOribasius(4 ${ }^{\text {th }}$ century CE)", BJU International. Voi.84,no.1,pp. 16-19,1999. View at publisher.

[3]. E. D. Smith, "The history of hypospadias", Pediatric Surgery International, vol. 12, no. 2-3, pp. 81-85, 1997.

[4]. Uday s. Chatterjee and Subir k. Chatterjee, 'Regenerative urethroplasty in reoperativehypospadias : buried strip principle revisited', J Indian AssocPediatr Surg. 2012 APR-JUN;17(2):63-67

[5]. Browne D. An operation for hypospadias. Proc R Soc Med. 1949; 41: 466

[6]. E. Durham Smith, ' The history of hypospadias, pediatrSurgInt ( 1997) 12: 81-85

[7]. OmarFahmy, 'Algorithm for optimal Urethral Coverage in hypospadias and fistula repair : a systemic review', European urology 70 (2016) 293-298

[8]. P. O. Hosli, “Einetechnikzumvershluss von harnrohrenfistein', Urology, vol. 9, p.129, 1970.

[9]. Rich MA, Keating MA, Snyder HM, Duckett JW. Hing the urethral plate in hypospadias meatoplasty.J Urol. 1989; 142:1551-3.

[10]. Shanberg AM, Sanderson K, Duel B. Re-operative hypospadias repair using Snodgrass incised plate urethroplast. BJU Int.2001;87:544-7.

[11]. Soylet Y, Gundogdu G, Yesildag E, Emir H. Hypospadias reoperations. Eur JPediatr Surg. 2004;14:188-92.

[12]. Al-Sayyad A, Pike JG, Leonard MP. Redo hypospadias repair: Experience at a tertiary care children's hospital. Can UrolAssoc J. 2007;1:47

[13]. Johanson B. Reconstruction of the male urethra in stricture: Application of the buried intact epithelium technic. ActaChir Scand. 1953;176:3-6.

[14]. Smith ED. A de-epithelised overlap flap technique in the repair of hypospadias. Br J Plast Surg. 1973;26:106-14

[15]. Bleustein CB, Esposito MP, Soslow RA, Felsen D, Poppas DP. Mechanism of healing following the snodgrass repair. J Urol. 2001;165:277-9.

[16]. Sarhan O, Saad M, Helmy T, Hafez A. Effect of suturing technique and urethral plate characteristics on complication rate following hypospadias repair: A prospective randomized study. J Urol. 2009;182:682-6.[PubMed

[17]. Holland AJ, Smith GH.Effect of the depth and width of the urethral plate on tabularized incised plate urethroplasty. J Urol. 2000;164:489-91. [PubMed] and Medical Sciences (IOSR-JDMS) 16.7 (2017): 75-80 